\title{
A ORGANIZAÇÃO DO TRABALHO DIDÁTICO NA DISCIPLINA HISTÓRIA NO GINÁSIO FREI ROGÉRIO (1943-1961)1
}

\author{
Isabela Toscan Mitterer \\ Universidade do Oeste Catarinense \\ isamitterer@hotmail.com
}

Sandino Hoff

Universidade Tuiuti do Paraná

sandino.hoff@terra.com.br

\section{RESUMO:}

O objeto desta pesquisa foi a organização do trabalho didático na disciplina História no Ginásio Frei Rogério, no período de 1943 a 1961. Os componentes investigativos fundaram-se na categoria de Organização do Trabalho Didático envolvendo três aspectos: a relação educativa, a mediação dos recursos didáticos e o espaço físico. Verificar como se organizou historicamente o trabalho didático na disciplina História no Ginásio Frei Rogério foi o objetivo estabelecido. Alcançá-lo implicou pesquisa bibliográfica e documental. Partimos do pressuposto de que há uma conexão íntima entre o trabalho didático e a forma de ser de uma instituição escolar. A análise ao permitir o entendimento das práticas escolares, que seguia as instruções impostas pelo Ministério da Educação, permitiu-nos entender a organização do trabalho didático no âmbito do Frei Rogério. A História, cuja função é formar cidadãos conformados à ordem dominante, também no Frei Rogério foi organizada de forma a cumprir essa função. $\mathrm{O}$ aspecto singular é dado pela vertente religiosa: formar o cidadão não apenas "virtuoso", mas também "bom cristão". Igreja e Estado caminhavam juntos defendendo os mesmos interesses.

Palavras-chave: Organização do Trabalho Didático, História, Ginásio Frei Rogério.

\section{WORK DIDACTIC ORGANIZATION IN SUBJECT TEACHING HISTORY IN GYM FREI ROGÉRIO (1943-1961)}

\begin{abstract}
:
The object of this research was the organization of the didactic work in the discipline in the history Gym Frei Rogério, in the period 1943 to 1961. Investigative components were founded in the category of Work of Didactic Organization involving three aspects: the relationship of education with the mediation of didactic resources and physical space. Check as historically organized labor discipline in teaching history at the Gym Frei Rogério was the stated goal. Access it involved literature and documents. We assume that there is an intimate connection between the teaching work and how to be an educational institution. The analysis by allowing the understanding of school practices, which followed the directions set by the Ministry of Education, has allowed us to understand the organization of the didactic work in the Frei Rogério. History, whose function is to train people conformed to the dominant order, also in Frei Rogério was organized in order to fulfill this function. The unique aspect is given by the sect: make citizens not only fruitful but also "good Christian". Church and state were walking together defending their interests.

Keywords: Organization of the teaching, History, Gym Frei Rogério.
\end{abstract}




\section{INTRODUÇÃO}

Inserida no projeto A História da Organização do Trabalho Didático2, cujo objetivo foi reconstruir a história da educação escolar ocorrida na região do Vale do Rio do Peixe, oeste de Santa Catarina, esta pesquisa tem como objeto a organização do trabalho didático na disciplina História ministrada no Ginásio Frei Rogério, no período de 1943 a 1961.

A raiz do Ginásio Frei Rogério está no município de Cruzeiro do Sul, atual Joaçaba, que instalou o primeiro grupo escolar em 1935 e o ensino secundário oito anos depois, em decorrência da expansão da rede escolar marista em Santa Catarina. A rede marista instalou, em 1938, sua unidade pioneira em Caçador, entendendo-se pelo Vale do Rio do Peixe. Nesse movimento, em 1943 o Ginásio Frei Rogério abriu a primeira turma.

A questão da identidade da ciência e do saber escolar, ao redor da qual gravita a história das disciplinas, toma uma dimensão particular no caso da História. Especificamente, nos conteúdos prescritos para essa disciplina pensa-se, explicitamente, a formação da sociedade que está no centro das pressões sociais. O processo de seleção dos conteúdos é cuidadoso, medido e assegurado, pois, havia necessidade política de depuração dos textos da História e, nestes, o reforço dos sentimentos patrióticos. As bases do conhecimento da disciplina no ensino ginasial ultrapassam a história da família, da cidade e da região; seu ensino amplia esse conhecimento ao passado da humanidade, estudo requisitado para a seleção nos cursos superiores. Logo, a disciplina tem funções a desempenhar. Além disso, o ensino ginasial foi o lugar das ambições das famílias de Cruzeiro do Sul.

A partir das considerações supracitadas emerge a problematização dessa investigação: como se deu o desenvolvimento histórico-temporal da disciplina História? A que necessidade social a disciplina atende? Qual a sua função? Qual a relação entre os conteúdos prescritos e os conteúdos realmente ensinados no Frei Rogério? Como a prática escolar do Ginásio Frei Rogério organizou esta disciplina? Com que finalidades?

Verificar como se organizou historicamente o trabalho didático na disciplina História, elaborada para o ensino ginasial e efetivada no Ginásio Frei Rogério, no intuito de interpretar o sentido de sua identidade e de sua singularidade foi o objetivo estabelecido para essa investigação. Alcançá-lo implicou, primeiramente, por meio de pesquisa bibliográfica, descrever o desenvolvimento histórico temporal da disciplina. A seguir, utilizando-se de pesquisa documental legislação, estatutos da escola, atas, pontos para provas, normas metodológicas, conteúdos programáticos, propostas pedagógicas e relatórios - buscou-se respostas para as seguintes questões: explicitar as práticas escolares efetuadas na disciplina História no Ginásio Frei Rogério, buscando por meio da relação conteúdos prescritos/conteúdos ensinados o lugar e as funções que a História exerceu.

Pressupõe-se que há uma conexão íntima entre o trabalho didático e a forma de ser de uma instituição escolar. A análise da disciplina História desvela a conexão existente entre as formas dessa instituição escolar e as formas do trabalho didático, de um lado, e, de outro, as práticas escolares e as funções sociais que cumprem.

O desenho desse artigo traz, após a introdução, a fundamentação teóricometodológica que guiou a investigação. No terceiro item traçamos um breve histórico do Ginásio Frei Rogério e, no quarto algumas notas sobre a pedagogia marista. Apresentamos uma síntese do desenvolvimento histórico temporal da disciplina História no quinto item. A descrição e a análise dos dados compõem o sexto item. Por fim, a análise das fontes bibliográficas e documentais, ao permitir o entendimento das práticas escolares, permitiu entender a organização do trabalho didático no âmbito do Ginásio Frei Rogério, no período 
de 1943 a 1961, revelando, também, um novo tema que aguarda a presença dos pesquisadores.

\section{A FUNDAMENTAÇÃO E OS CAMINHOS DA INVESTIGAÇÃO}

O projeto exigiu pesquisa bibliográfica e documental. A investigação, ao mergulhar no interior da instituição escolar, desvelou os conteúdos ensinados na disciplina História a partir da legislação, dos estatutos da pedagogia marista e das ciências de referência.

O caminho escolhido para adentrar a instituição foram as práticas escolares da disciplina História, objeto singular da investigação. Os componentes investigativos fundaram-se na categoria de Organização do Trabalho Didático. Trata-se de uma categoria dialética, universal e abstrata que apreende a historicidade das propostas e práticas educacionais; e de uma categoria subalterna à categoria do trabalho material, sendo de natureza não-material. A Organização do Trabalho Didático envolve três aspectos:

a) ela é, sempre, uma relação educativa que coloca, frente a frente, uma forma histórica de educador, de um lado, e uma forma histórica de educando(s), de outro,

b) realiza-se com a mediação de recursos didáticos, envolvendo os procedimentos técnico-pedagógicos do educador, as tecnologias educacionais pertinentes e os conteúdos programados para servir ao processo de transmissão do conhecimento,

c) e implica um espaço físico com características peculiares, onde ocorre. (ALVES, 2005, p. 10-11).

Para desvelar esses aspectos buscamos trabalhar com as políticas públicas não em sua forma pura ou relacional com outras políticas, mas, a partir das práticas escolares, entendidas como o singular da pesquisa, reveladas nos documentos. O singular, bem investigado e inquirido em seus pormenores, revela toda a universalidade nele existente. Para alcançar tais resultados, a pesquisa documental buscou também atas, pontos para provas, normas metodológicas, conteúdos programáticos, propostas pedagógicas, relatórios e outras fontes disponíveis no Colégio Frei Rogério.

O recorte temporal toma como marco inicial a data do início das atividades da instituição, 1943, estendendo-se até 1961, quando no Brasil as Leis Orgânicas do Ensino foram substituídas por uma nova legislação educacional, a Lei 4.024/61.

Pesquisar a organização do trabalho didático da disciplina escolar História, efetivada no Ginásio Frei Rogério, adquire sentido quando é apreendida no contexto da sociedade e quando se considera a unidade dialética que existe entre a base material e a superestrutura das formações sociais das quais a educação é parte. Nesse sentido, as experiências e os resultados da organização fabril e do trabalho produtivo, próprios da base material, se articulam com o trabalho didático, transpondo seus métodos, suas tecnologias e sua racionalidade para a organização do trabalho didático.

A gênese da organização da escola e do trabalho didático ocorreu em inícios da Modernidade, na passagem da forma individual para a forma coletiva de ensino. Conforme Alves (2005, p. 63), Comenius (1592-1670) instituiu a escola e a organização de ensino, cuja estrutura básica subsiste na atualidade. $\mathrm{O}$ importante a entender é que a instituição escolar, como existe hoje, foi pensada e construída pelos pedagogos modernos; os grupos escolares, criados em inícios do século XX no Brasil, apresentam-se como a consolidação da organização manufatureira do trabalho didático: dezenas de alunos, reunidos no mesmo lugar sob a direção de um professor, aprendem a mesma lição, ao mesmo tempo, utilizando o instrumento comum que é o manual didático. E só "conseguiremos superá-la quando 
rompermos com a didática comeniana e ratiquiana em vigor, e entendê-la quando aprendermos que há certas coisas que só começaremos a perceber quando nos dispusermos a remontar às fontes" (HOFF, 2005, p. 39).

A história da disciplina História no ensino ginasial, matéria que à época moderna ainda não tinha conquistado sua autonomia, é aqui estudada como uma atividade escolar inserida na organização manufatureira do trabalho didático. No interior dessa discussão "o pressuposto é que a organização do trabalho didático é histórica. Mais apropriado seria falar, então, em formas históricas de organização do trabalho didático, produzidas pelas diferentes épocas para atender necessidades sociais correspondentes" (ALVES, 2005, p. 2).

Ao investigar uma das disciplinas que compõe o núcleo comum da grade curricular do ensino ginasial o emprego do termo disciplina escolar será constante, havendo necessidade de precisar esse conceito.

Conforme Chervel (1990), em seu artigo História das Disciplinas Escolares: reflexões sobre um campo de pesquisa, até o final do século XIX, o termo disciplina e a expressão "disciplina escolar" designavam tão somente a vigilância dos estabelecimentos e a repressão às más condutas. Em 1870, o termo fez par com o verbo disciplinar e passou a designar um sinônimo de ginástica intelectual a disciplinar a inteligência das crianças. No sentido de conteúdos de ensino, o termo aparece somente nos primeiros anos do século XX quando "passa a significar matéria de ensino suscetível de servir de exercício intelectual" (CHERVEL, 1990, p. 179). O termo disciplina se aplica tão somente às idades de formação, seja ela primária ou secundária; são modos de transmissão cultural que se dirigem aos alunos. Aplicadas nas idades de formação, "as disciplinas escolares fazem parte dos currículos e constituem saberes [...] que circulam no cotidiano das salas de aula" (BITTENCOURT, 2003, p. 9).

A disciplina História foi investigada não de forma fragmentada, mas inserida na organização do trabalho didático do Colégio Frei Rogério que, por sua vez, está inserido no movimento social maior. Buscando desvelar esse movimento os itens seguintes apresentam um breve histórico do Colégio e os principais fundamentos pedagógicos da rede marista.

\section{BREVE HISTÓRICO DO COLÉGIO MARISTA FREI ROGÉRIO3}

Conforme Detoni (2003), os irmãos Maristas chegaram ao Brasil, no dia 18 de outubro de 1897. Até 2002, desenvolveram-se em quase todos os estados brasileiros: "sua atuação engloba comunidades, colégios, editoras, meios de comunicação social, obras sociais, universidades e centros de formação humana." (2003, p. 49). Nesse período, o trabalho nos colégios foi o que adquiriu maior relevância: são cerca de 80 escolas, dentre elas o Colégio Frei Rogério.

Essa significativa expansão não só da rede marista como também de outras congregações religiosas deveu-se a um contrato assinado entre a Sociedade Literária Padre Antônio Vieira e o Governo de Santa Catarina, em 1920, no qual o governo catarinense

[...] se comprometia a não abrir nenhum "ginásio oficial" no território catarinense por 25 anos (Termo, 1920, pp.285-87). Esse contrato entrou em vigor em 1 de janeiro de 1921, de maneira que, até 1946, estabeleceuse a privatização absoluta do ensino secundário em Santa Catarina (DALLABRIDA; CARMINATI, 2007, p. 17-18).

Em solo catarinense a obra marista teve início em 1938, em Caçador, com a fundação do Colégio Aurora. O Ginásio Frei Rogério iniciou seus trabalhos, em 11 de abril de 1943, atendendo aos anseios da comunidade de Cruzeiro do Sul, hoje Joaçaba, que "desejava uma educação mais aprimorada para seus filhos, não tolerando a carência do 
ensino ginasial naquele município, que já na época se destacava econômica e industrialmente." (http://www.marista.org.br/marista-rrei-rogerio/D9)4. A instituição iniciou suas atividades com a $1^{\mathrm{a}}$ série do ensino secundário ginasial e o curso preparatório, contando com 90 alunos. O ensino secundário era composto pelo ensino ginasial e pelo colegial, correspondendo respectivamente às atuais quatro séries finais do Ensino Fundamental e ao Ensino Médio.

Entre 1943 e 1963 foram fundados quatro grêmios: o Grêmio Literato-Esportivo (1943) cuja finalidade era promover sessões cívicas e esportivas; suas apresentações iniciavam-se com o Hino Nacional, o Hino do Ginásio, declamações, cantos e comemorações alusivas ao dia. O Grêmio Literário José de Alencar (1948) que reunia os alunos da $3^{\text {a }}$ série ginasial, o Grêmio Literário Castro Alves (1949) reunindo os alunos da $4^{\text {a }}$ série ginasial e o Grêmio Estudantil Frei Rogério (1963) que diferenciava-se dos anteriores pelo tema de suas apresentações que versavam sobre assuntos da época e datas comemorativas.

Em 1953, atendendo aos preceitos maristas constantes na Constituições e Estatutos - Roma, 1906 (Apud Martins, 2003, p. 14-15) que consideram a convivência familiar de extrema importância no processo educativo, foi criada, no Frei Rogério, a Associação de Pais e Mestres.

Atendendo também às necessidades do mercado, foram instalados, em 1954, cursos técnicos, como o curso Técnico de Contabilidade. Também nesse período o Ginásio Frei Rogério firmou parceria com o SENAC destinando cursos à aprendizagem e ao aperfeiçoamento de trabalhadores para atuarem nas indústrias e no comércio, incluindo aí o curso feminino Técnico em Comércio. Em 1964, criou-se o Sistema de Ginásio Orientado para o Trabalho (GOT), em parceria com o MEC, que ofereceu espaço às oficinas de técnicas industriais e agrícolas, para suprir a necessidade de mão-de-obra especializada nesses setores.

Não nos esqueçamos que entre os anos de 1945 e 1960 ocorreram os embates entre os escolanovistas, defendendo a escola pública, laica e gratuita e os católicos que afirmavam que a escola leiga e estatal não educava apenas instruía, portanto os pais deveriam ter liberdade de escolha para a educação de seus filhos.

Em 1971, iniciou-se o Colégio misto. Em 1976, já sob a vigência da Lei 5.692/71, o Ginásio Frei Rogério implantou os cursos de Auxiliar de Contabilidade, Auxiliar de Escritório e Assistente de Administração. Nesse mesmo ano recebeu autorização do Conselho Estadual de Educação para o funcionamento do Segundo Grau. Mais tarde, incluiu-se o Curso de $2^{\circ}$ Grau matutino com Habilitação Básica em Eletricidade. A autorização para o funcionamento do $1^{\circ}$ Grau, $1^{\text {a }}$ a $4^{\mathrm{a}}$ série, ocorreu em 1979 . Por fim, a autorização para o funcionamento do Pré-Escolar ocorreu em 10 de dezembro de 1986.

O Colégio, - que sempre foi dirigido pelos Irmãos Maristas, embora conte, também, com a colaboração de leigos - recebeu o nome de Ginásio Frei Rogério em homenagem ao missionário franciscano frei Rogério, vigário de Lages, a cuja paróquia pertencia o Vale do Rio do Peixe. Ao longo de seus 65 anos o Ginásio Frei Rogério, hoje Colégio Marista Frei Rogério, ampliou suas instalações, melhor auxiliando "na concretização do sonho de São Marcelino, o fundador do Instituto dos Irmãos Maristas, que era formar bons cristãos e virtuosos cidadãos" (http://www.marista.org.br/marista-rreirogerio/D9).

\section{FUNDAMENTOS PEDAGÓGICOS DA CONGREGAÇÃO MARISTA}

Conforme Martins (2003) a rede marista está presente em 76 países, nos quais a Congregação mantém colégios, centros sociais, hospitais e universidades. No Brasil, eles 
são responsáveis por 80 colégios, 3 universidades e 100 centros sociais, contando com cerca de 142.226 alunos.

A proposta educacional da Congregação Marista fundamenta-se nas idéias de Champagnat que insistia com seus discípulos, dizendo-lhes que não era suficiente serem bons professores, deveriam ser mais do que isso, pois não se tratava "de ensinar apenas as ciências humanas, mas preparar o homem todo: seu coração, sua mente, sua vontade e sua liberdade". Portanto, os institutos dos Irmãos Maristas têm como objetivo educar o aluno por inteiro. O professor deve atuar no grupo e no meio dos alunos.

O Le Guide des Écoles, publicado em 1853, é a base da proposta educacional marista. É o texto-síntese no qual se apóiam as reflexões e experiências sobre as instituições e as orientações de Marcelino Champagnat. Com o intuito de manter-se criativo o texto já passou por diversas atualizações, sendo a mais recente entre 1995 e 1998. Mantendo-se fiel ao legado de Champagnat, esse guia continua inspirando toda a ação marista na educação.

Martins, irmão marista, apoiando-se no Le Guide des Écoles e outros documentos da Congregação publicou, em 2003, O Estilo Marista de Educar. O livro apresenta as principais características da abordagem pedagógica marista proposta por Champagnat, nas quais se fundamenta a proposta da Pontifícia Universidade Católica do Rio Grande do Sul.

Conforme a pedagogia proposta por Champagnat, "no ensino, o fim principal não é encher a cabeça do educando de conhecimentos úteis, mas proporcionar-lhe meios de adquiri-los. Para tanto, deve desenvolver, dirigir e cultivar as faculdades intelectuais, a fim de colocá-las em situação de tirar proveito delas ao longo da vida" (Guide des Écoles, p. 113. Lyon, France, 1853. Apud MARTINS, 2003, p. 16).

Nesse sentido, destacam-se cinco características básicas na pedagogia marista: integralidade; presença amiga do professor; modelo familiar e de simplicidade; pedagogia do trabalho e da constância; e pedagogia da motivação e da competência profissional. A primeira e a quarta estão presentes desde 1853; a terceira entra nos documentos a partir de 1906; a segunda e a quinta foram inseridas em 1996.

Por integralidade a proposta marista entende educar o aluno por inteiro, buscando favorecer seu crescimento integral, "não se interessando apenas pela aprendizagem de conteúdos, de habilidades e de hábitos, mas considerando a pessoa na sua totalidade" (MARTINS, 2003, p. 10). Nesse sentido, fomenta a interpretação cristã da vida na família, no trabalho e na sociedade, transmitindo o sentido de Deus e o sentido de homem.

O professor deve atuar no grupo e no meio dos alunos: "para ser bom educador, diz Champagnat, é indispensável que conviva com o aluno todo o tempo de que dispuser" (MARTINS, 2003, p. 12). Sua presença deve ocorrer espontaneamente, como exemplo de sua ação educativa, daquilo que ensina e daquilo que faz.

Conforme o texto Constituições e Estatutos - art.49 - Roma, 1906 (apud Martins, 2003 , p. 14) "as primeiras comunidades maristas eram um modelo familiar. Champagnat conseguiu organizar comunidades vivas, dinâmicas, baseadas no amor mútuo. Formavam um ambiente familiar simples e mariano, convictos de que não existe educação sem família." Portanto, para a educação marista a família é o ambiente educativo por excelência e a simplicidade a melhor virtude.

Para Champagnat o fim principal da educação é proporcionar aos educandos os meios pelos quais eles poderão adquirir os conhecimentos úteis. Para tanto, "o valor pessoal e intelectual necessita ser sustentado e desenvolvido por um ininterrupto trabalho disciplinado de estudo e de cultivo pessoal" (MARTINS, 2003, p. 17). Adere-se a uma pedagogia do trabalho e da constância desenvolvendo hábitos pessoais de pontualidade, de juízo crítico, de estudo, de planejamento e de atualização em técnicas de aprendizagem. 
A proposta de uma pedagogia da motivação e da competência profissional deve, conforme Martins (2003, p. 19), levar o educando a reconhecer e a aceitar as dificuldades diárias e transformá-las em desafios de superação pessoal: trabalho, dedicação, esforço e constância na função educativa. Deve levá-lo a estar aberto às inovações pedagógicas e tecnológicas, às necessidades formativas e educativas transformadoras da sociedade.

É sabido que toda proposta pedagógica implica uma visão de mundo e de homem. Martins (2003, p. 25) explicita qual é essa visão, segundo a Congregação Marista:

1 - Nossa visão do mundo e do ser humano está inspirada no Evangelho de Jesus Cristo.

2 - Consideramos o mundo como um lugar onde os homens e as mulheres dialogam entre si e se irmanam num esforço comum para construir uma sociedade justa, consciente e solidária.

3 - Cremos no ser humano como valor supremo da Criação e em sua capacidade de descobrir o bem e a verdade, que se assume como projeto de uma permanente conquista de si mesmo, como sujeito e autor de sua própria história.

4 - O domínio respeitoso do homem e da mulher sobre a Criação deve colocá-los a serviço da realização da pessoa e de toda a comunidade humana. Conseqüentemente, todas as estruturas econômicas, sociais, políticas e jurídicas, devem reconhecer, no ser humano, sua razão de ser. 5 - O educador marista vê o ser humano como uma pessoa livre e original, investida de dignidade, responsabilidade e esperança, em interação com a natureza, com os demais homens e com Deus.

(Ideário Educativo Marista - Províncias Maristas de Rio de La Plata y Córdoba - Argentina. Apud MARTINS, 2003, p. 25).

A leitura do livro de Martins (2003) - Estilo Marista de Educar - revela o alto teor religioso contido na proposta pedagógica marista que tem em Jesus o exemplo maior e em Maria, o modelo perfeito de educadora, conforme afirma o irmão marista:

[...] Nele (em Jesus) (os professores) encontrarão as características do verdadeiro Estilo Marista de Educar: convivência constante e amiga; espontaneidade no relacionamento; exemplo vivo de vida; atitude permanente de amor recíproco; pedagogia da presença, da simplicidade e da autêntica comunicação; linguagem simples, acessível aos discípulos e ao povo; recurso didático: figuras, imagens, símbolos, parábolas para melhor transmitir e incutir seus ensinamentos; preocupação constante com a formação integral, como preparação para a árdua missão de seus discípulos; doação total da vida até à própria morte (MARTINS, 2003, p. 27).

Maria é, de todos os tempos, o modelo perfeito do Educador Marista. [...] Como educadora de Jesus, na escola familiar de Nazaré, propicia a seu filho Jesus a possibilidade de "crescer em estatura, sabedoria e graça" ( $\mathrm{Lc} 2,52)$, desenvolvendo nele suas potencialidades, preparando-o para a vida e para a grandeza da Missão futura (MARTINS, 2003, p. 29).

Para Martins (2003, p. 29) o educador marista deve assumir todos os aspectos mariais de educar: "amor pelo educando, simplicidade e dedicação, doação total sem reservas, afeto e respeito no relacionamento, carinho nas relações interpessoais", pois o educador marista "não é um simples professor. É muito mais do que isso: é um educador por completo". 
Os princípios citados nesse item têm aplicação em toda a rede de ensino marista. Portanto, o Colégio Frei Rogério, assim como todos os outros colégios maristas, deve buscar, por meio deles, "formar bons cristãos e virtuosos cidadãos".

Como a disciplina História é adequada a esses princípios? Precede a essa questão a origem e o desenvolvimento histórico da disciplina.

\section{DESENVOLVIMENTO HISTÓRICO-TEMPORAL DA DISCIPLINA HISTÓRIA}

Considerou-se, para a investigação, o conceito de disciplina como um conjunto de conhecimentos, elaborado por especialistas, identificado e dotado de organização própria para o estudo e, que, ao vincular-se à escola, estabelece novas relações de saber pela prática dos professores e alunos.

A disciplina História nem sempre se constituiu como disciplina escolar. Segundo Fonseca (2003), os conteúdos de História, destinados ao ensino, só ganharam importância a partir da necessidade de formar as elites. Embora os colégios jesuítas, no século XVI, já apresentassem temas de História em seus currículos, eles não integravam um conjunto organizado de saberes e de procedimentos que caracterizassem uma disciplina escolar.

Foi no início do século XIX, continua Fonseca (2003, p. 23), na França, que a História se constituiu como disciplina escolar, quando a organização dos sistemas de ensino público passou a preocupar-se com a formação de um cidadão adequado às transformações do sistema social e econômico provocadas pela consolidação do capitalismo e pelo fortalecimento das identidades nacionais. Cabia à disciplina

[...] apresentar às crianças e aos jovens o passado glorioso da nação e os feitos dos grandes vultos. Esses eram os objetivos da historiografia comprometida com o Estado e sua produção alcançava os bancos das escolas por meio dos programas oficiais e dos livros didáticos, elaborados sob estreito controle dos detentores do poder. Isso ocorreu na Europa e também na América (FONSECA, 2003, p. 25).

O Colégio Pedro II, criado em 1837, no Rio de Janeiro organizou os primeiros conjuntos de saberes que se constituiriam em disciplinas escolares. A disciplina História foi instituída sob a influência francesa, onde predominou a História da Europa Ocidental apresentada como a verdadeira História da Civilização. A História Sagrada foi mantida porque religião e Império estavam unidos. A História Pátria, cuja tarefa era formar para a nacionalidade ocupava papel secundário, permanecendo, por muito tempo, dentro dos registros da História Universal. Mas foi com esse objetivo e direcionada para o ensino secundário que a História Pátria consolidou-se, em 1848, no Colégio Pedro II, como disciplina escolar autônoma. A definição dos saberes sobre o passado nacional a serem divulgados e ensinados ocorreu nos anos de 1860, sob a orientação do Instituto Histórico e Geográfico Brasileiro - IHGB, que deveria

[...] construir a genealogia nacional, no sentido de dar uma identidade à nação brasileira e formar, através do ensino de História, uma ciência social geral que (ensinasse) aos alunos, ao mesmo tempo, a diversidade das sociedades do passado e o sentido de sua evolução (ABUD, 2004 p. 30).

O ensino de História, altamente político e nacionalista, enaltecia a colonização portuguesa, a ação missionária da Igreja Católica e a monarquia.

A partir de 1930 o Estado assumiu diretamente a direção da educação no Brasil, que até então estava subordinada às províncias que seguiam os programas do Colégio Pedro II. Os programas do ensino secundário, bem como as instruções metodológicas 
passaram a ser expedidos pelo recém-criado Ministério da Educação e Saúde Pública que, objetivando reforçar os sentimentos patrióticos da população, cuidou "da constituição da galeria dos heróis nacionais, pela instituição tanto de feriados e festas cívicas quanto da seleção dos personagens a serem cultuados no ensino" (NADAI, 1992/1993, p. 151).

A Reforma Francisco Campos (1931) determinava que os conteúdos de História fossem organizados por série e abrangessem a História Geral, do Brasil e da América. As instruções metodológicas buscavam fortalecer o sentimento de identidade nacional, num processo de uniformização que "permitisse o ocultamento da divisão social e a direção das massas pelas elites" (ABUD, 2004, p.34). Embora consideradas o centro do ensino, a História do Brasil e da América estavam diluídas na História da Civilização.

Em 1942, foi a Reforma Capanema que estabeleceu novos currículos, predominantemente enciclopédicos e valorizando a cultura geral e humanística. A Geografia e a História Pátria eram disciplinas autônomas e junto com a Educação Moral e Cívica, tinham a finalidade de garantir um estudo mais aprofundado da realidade do país.

Ainda sob a vigência da Reforma Capanema os programas para o ensino de História passaram por algumas alterações que pouco se afastaram das concepções e das práticas tradicionais. Estas alterações foram promovidas pelo Ministério da Educação, em 1951, fazendo uma redistribuição da seriação dos conteúdos para os cursos ginasial e colegial.

Durante a ditadura militar, a disciplina foi posta a serviço do regime que defendia a formação de cidadãos ordeiros e de valores patrióticos, além de formá-los para o mercado de trabalho, conforme imposição da Lei 4.024/61.

Em 1971, a Lei n ${ }^{\circ} 5.692$ fundiu História e Geografia, anteriormente disciplinas autônomas, em Estudos Sociais para o ensino no Primeiro Grau (MEC. Parecer 853/71) e no Segundo Grau, embora a disciplina História tenha sido mantida, teve sua carga horária e conteúdos reduzidos, comprometendo significativamente seu ensino, buscando formar jovens obedientes à nova ordem. Por essa lei os conteúdos de História, Geografia, Educação Moral e Cívica e OSPB deveriam ser trabalhados de forma sistemática e integrada. Somente na década de 1980, a História volta como disciplina autônoma no ensino de primeiro Grau.

Ainda na vigência da Lei 5.692/71 o núcleo comum do Ensino de Primeiro e Segundo Graus, até então regidos pela Resolução n ${ }^{\circ} 8 / 71$, anexa ao Parecer $n^{\circ}$ 853/71, foi alterado pela Resolução 6/86 e pelo Parecer 785/86. Pelo novo Parecer, História e Geografia voltaram a ser disciplinas distintas. Nas séries iniciais do Primeiro Grau a denominação de Estudos Sociais foi mantida, porém, sem a exigência de aglutinação. De $5^{\text {a }}$ a $8^{\text {a }}$ série a integração dos conteúdos de Estudos Sociais foi desfeita, voltando a se constituir a História, a Geografia e OSPB e, no Segundo Grau, permaneceram a História e a Geografia.

As propostas, elaboradas a partir da LDB 9.394/96, para as séries finais do Ensino Fundamental basearam-se em uma História social ou sociocultural. Os conceitos são considerados básicos para o conhecimento histórico, destacando-se os de cultura, trabalho, organização social, relações de poder e representações. Para Bittencourt (2005, p. 116), o domínio de tais conceitos torna-se relevante para assegurar a sistematização dos conteúdos porque existe um elenco de conteúdos predeterminados para cada série e de propostas baseadas em eixos temáticos ou em temas geradores.

Cardoso (2006), ao analisar os estudos de Bittencourt conclui que a disciplina História tem permanecido nos currículos, com a função de formar o cidadão crítico, ativo e consciente de seus limites e de suas possibilidades, revelando que os currículos oficiais de História têm a intenção explícita de formar esse cidadão. No entanto, a concepção de 
cidadão resguardada nesses currículos é a do cidadão político, ou seja, o eleitor, o indivíduo instruído para cumprir bem seus deveres e conhecer seus direitos, não o cidadão social, aquele com direitos de usufruir os bens socialmente produzidos e que, além de cumprir com os seus deveres e conhecer os seus direitos seja capaz de exercê-los sem depender de outrem. Esse cidadão é compatível com o cidadão virtuoso e bom cristão objetivado pela pedagogia marista?

\section{A ORGANIZAÇÃO DO TRABALHO DIDÁTICO NA DISCIPLINA HISTÓRIA NO GINÁSIO FREI ROGÉRIO}

Como já foi dito no item 2, sobre a fundamentação teórica, os componentes investigativos fundaram-se na categoria de Organização do Trabalho Didático que envolve três aspectos: a relação educativa, a mediação dos recursos didáticos e o espaço físico. A análise desses aspectos permitiu-nos fazer aflorar a identidade e a singularidade da organização histórica do trabalho didático na disciplina História, elaboradas para o ensino ginasial e efetivadas no Ginásio Frei Rogério, revelando suas funções.

\subsection{A RELAÇÃO EDUCATIVA}

Conforme descrevemos no item 4 , um dos fundamentos da pedagogia marista é a presença amiga do professor. Para Champagnat não bastava ser bom professor, era preciso ser educador: "não se trata de ensinar apenas as ciências humanas, mas preparar o homem todo: seu coração, sua mente, sua vontade e sua liberdade".

Para a população joaçabense o Colégio Frei Rogério cumpria bem sua missão educativa. Detoni (2003, p. 48) destaca elogios registrados na imprensa local, à época da formatura, pelos relevantes serviços prestados pelo Ginásio à mocidade do oeste catarinense "na patriótica causa do desenvolvimento cultural de Santa Catarina".

Sobre o professor da cadeira de Português que proferiu a aula inaugural do curso técnico, em 1955, escreveu o mesmo jornal:

[...] o Professor Walter Francisco Bezerra, da cadeira de Português, que soube demonstrar grande facilidade e conhecimentos acerca da línguaprática, expondo, com segurança, a importância que representa a um povo o manejo do próprio idioma. A referida aula inaugural, que contou com o comparecimento de quase todo o corpo docente e discente da referida Escola Técnica, soube deixar nos presentes, merecidamente, a melhor das impressões (Tribuna Livre n.51 de 13 mar. 1955 p. 5. Apud DETONI, 2003, p. 54).

Também no Relatório para Fins de Reconhecimento/1953 encontramos evidências da eficiência do corpo docente:

O ensino ministrado pelo Ginásio Frei Rogério é eficiente porque seus professores estão devidamente habilitados de conformidade com as exigências legais e seguem as instruções metodológicas da Diretoria do Ensino Secundário para as diversas disciplinas do primeiro ciclo secundário. As promoções nas diferentes séries ginasiais variam entre $60 \%$ a $80 \%$.

Junto ao relatório consta o atestado assinado por Leônidas Menel, inspetor federal responsável pelo Frei Rogério desde 1948, no qual atesta, nesse período, a perfeita regularidade das atividades escolares comprovada por isenção de penalidades; pela não interrupção das aulas por falta de professor; e pela permanência habitual do diretor. 
As exigências legais citadas pela Comissão referem-se ao capítulo XXI da Portaria $n^{\circ}$ 501/1952 que dispõe, em treze artigos, as condições para o exercício do magistério no ensino secundário. Dentre elas destacamos: prova de habilitação para o magistério, prova de idoneidade moral, folha corrida, idade mínima de 21 anos, prova de quitação com o serviço militar, atestado de sanidade física e mental, prova de identidade.

Em seus primórdios, o quadro docente do Ginásio Frei Rogério era composto essencialmente pelos irmãos maristas. Detoni (2003, p. 73) afirma que o Ginásio "contava com um professor leigo para lecionar Educação Física, [...] lembrando que esta disciplina seguia o Guia Militar, reforçando a proximidade entre a Igreja e o Estado". Ainda assim o nível de exigência na seleção era considerável garantindo a eficácia do ensino que atendia, basicamente, aos filhos das mais distintas famílias, conforme atesta outro jornal da época: “o Ginásio Frei Rogério [...] diplomou mais uma turma de ginasianos composta de 18 jovens das mais distintas famílias de Joaçaba e Herval D' Oeste" (Jornal do Petebê, 1957, p. 18. Apud DETONI, 2003, p. 59).

O público alvo do Ginásio Frei Rogério eram os filhos de empresários e industriais oriundos de famílias economicamente bem situadas, embora os jovens mais necessitados também fossem atendidos pelos maristas, porém "pagavam" pelos seus estudos, como relata Detoni (2003, p. 49): "em uma entrevista o ex-aluno Modesto Detoni, conta-nos que no período em que estudou no então Ginásio Frei Rogério, ele e mais dois colegas eram internos e nada pagavam. Para que isso fosse possível tomavam conta da ordem e limpeza do refeitório e do dormitório".

Se, por um lado, tem-se o rigor do regulamento para o corpo docente, pelo outro não era diferente. Aos alunos, também, eram impostas regras disciplinares muito rígidas.

O Regulamento Interno/1944 traz, em seu quinto capítulo, os preceitos disciplinares obrigatórios a todos os alunos. São sete artigos dos quais destacamos apenas alguns itens: uso obrigatório do uniforme; conformidade com os preceitos da boa educação e da moral cristã - sobre seus hábitos, gestos, atitudes e palavras devem ter especial cuidado, obedecendo às regras que visam à ordem e à disciplina; comportamento digno e pontualidade. À autoridade, geralmente, e de modo especial ao diretor, aos professores e aos funcionários do estabelecimento devem os alunos: respeito e cortesia, tirando chapéu quando por eles passam ou com eles falam; obediência, executando as ordens e as determinações pronta, exata e alegremente; e submissão. Não se tolerava de forma alguma que o aluno respondesse em público quando advertido, censurado ou castigado. Quem julgasse não tem merecido a advertência, censura ou castigo deveria apresentar-se depois da aula, em particular, ao respectivo professor ou diretor expondo suas razões com franqueza e modéstia. Para as aulas e os estudos os alunos deveriam observar a pontualidade, a freqüência assídua às aulas, ao trabalho e ao esforço pessoal. Ficava banido tudo que pudesse perturbar a ordem, por exemplo: estalar os dedos, falar ou comunicar-se com os vizinhos, rir, etc. Era vedado aos alunos ler durante as aulas, escrever nas paredes ou móveis do Ginásio, perturbar a ordem e o silêncio.

As penalidades variavam desde a advertência simples, passando pela advertência com trabalho escrito para fazer em casa à retenção, privação total ou parcial do recreio até a exclusão do estabelecimento ou perda do ano pela proibição de prestar exames. A penalidade máxima era a exclusão dos estudos em quaisquer estabelecimentos nacionais, oficiais ou equiparados. O Regulamento não explicita como isso poderia ocorrer.

A rigidez da disciplina e a submissão imposta que tanto assusta atualmente era considerada normal àquela época. Exemplo disso é o relato que segue:

Um determinado dia, um colega dirigiu-se ao professor, como que se queixando do atendimento diferenciado que o entrevistado recebia 
daquele, dizendo, portanto que este era 'puxa-saco' do professor. O professor, um Irmão que Modesto não lembra o nome, chamou o colega e solicitou que trouxesse um saco e colocasse bolas de gude dentro dele. Ele assim o fez, então o Irmão ordenou que ele arrastasse o saco pelo pátio, na presença de todos. O aluno executou o castigo. Então o Irmão perguntou: Quem é ‘puxa-saco'? O caso encerrou-se ali (DETONI, 2003, p. 77).

Segundo citação de Martins (2003, p. 9) a proposta marista de educar teve como seu ponto de partida as reflexões e as práticas de Marcelino Champagnat, mas foi melhor elaborada e tematizada, ao longo dos anos, por diversas gerações de educadores maristas. Considerando esse fato teceremos uma breve comparação entre os preceitos disciplinares do Frei Rogério e apenas dois aspectos da proposta de Champagnat: o primeiro refere-se à organização de comunidades vivas, dinâmicas e baseadas no amor mútuo (Constituições $e$ Estatutos - art. 49 - Roma, 1906); o segundo, ao fim principal do ensino que seria proporcionar aos educandos os meios de adquirir os conhecimentos úteis para a vida. A extrema rigidez dos preceitos disciplinares impostos aos alunos para regular a relação educativa lembrava uma comunidade viva e dinâmica? Esse tipo de relação proporcionava meios de adquirir conhecimentos úteis para a vida?

Embora não tenhamos encontrado registros específicos da relação professor de História/alunos e de não termos realizado entrevistas podemos concluir que esta relação autoridade docente/submissão e obediência discente - se dava da mesma forma em todas as disciplinas, uma vez que ela deveria estender-se ao diretor, aos professores e aos funcionários do estabelecimento.

Dissemos, na introdução, que essa pesquisa além de permitir-nos entender a organização do trabalho didático na disciplina História no Ginásio Frei Rogério revelounos, também, um novo tema para pesquisas futuras. Ei-lo: a aparente (ou real) contradição entre a relação educativa proposta pela pedagogia de Champagnat e relação que se efetiva, a partir do Regulamento Interno do Ginásio Frei Rogério nas décadas de 1940, 1950 e 1960. Correlacionado está a centralidade do ensino no professor, aspecto essencial da pedagogia marista, enquanto a pedagogia escolanovista propunha a centralidade do ensino no aluno. Como isso repercutiu no interior de um colégio marista?

\subsection{A MEDIAÇÃO DOS RECURSOS DIDÁTICOS}

Conforme o Regulamento Interno do Ginásio Frei Rogério, datado de 1944, a finalidade do Colégio seria "proporcionar à mocidade uma sólida educação intelectual, moral, e cívica". Ele também dispõe sobre a fundamentação dos programas disciplinares a serem elaborados, estabelecendo que estes deveriam seguir a Lei Orgânica do Ensino Secundário - Portaria Ministerial no 170, de 11 de Julho de 1942. Conforme já foi exposto, na vigência dessa lei, os currículos eram predominantemente enciclopédicos, valorizando a cultura geral e humanística. A História Pátria era disciplina autônoma e, junto com a Geografia e a Educação Moral e Cívica, objetivava o estudo mais aprofundado da realidade brasileira.

O ensino de História passou por pequenas alterações promovidas pelo Ministério da Educação, em 1951, expressas, no ano seguinte, pela Portaria $n^{\circ}$ 501/1952 que expedia instruções para o ensino secundário. O primeiro capitulo dessa Portaria traz as instruções para o exame de admissão, prestado pelos alunos concluintes do ensino primário, cuja aprovação garantia o ingresso no curso ginasial, primeira fase do ensino secundário. Para a prova de História, exigia o domínio da História do Brasil.

No terceiro parágrafo do artigo $3^{\circ}$ consta que 
$\S 3^{\circ}$ - A prova escrita de História do Brasil constará de 20 questões simples e objetivas sobre o programa da disciplina, devendo dez das referidas questões versar sobre o Brasil independente. No julgamento da prova serão atribuídos até 10 pontos.

$\mathrm{O}$ artigo $13^{\circ}$ apresenta as matérias, para o ensino ginasial, dos programas de Português, Matemática, Geografia e História do Brasil, da qual destacamos a prescrição:

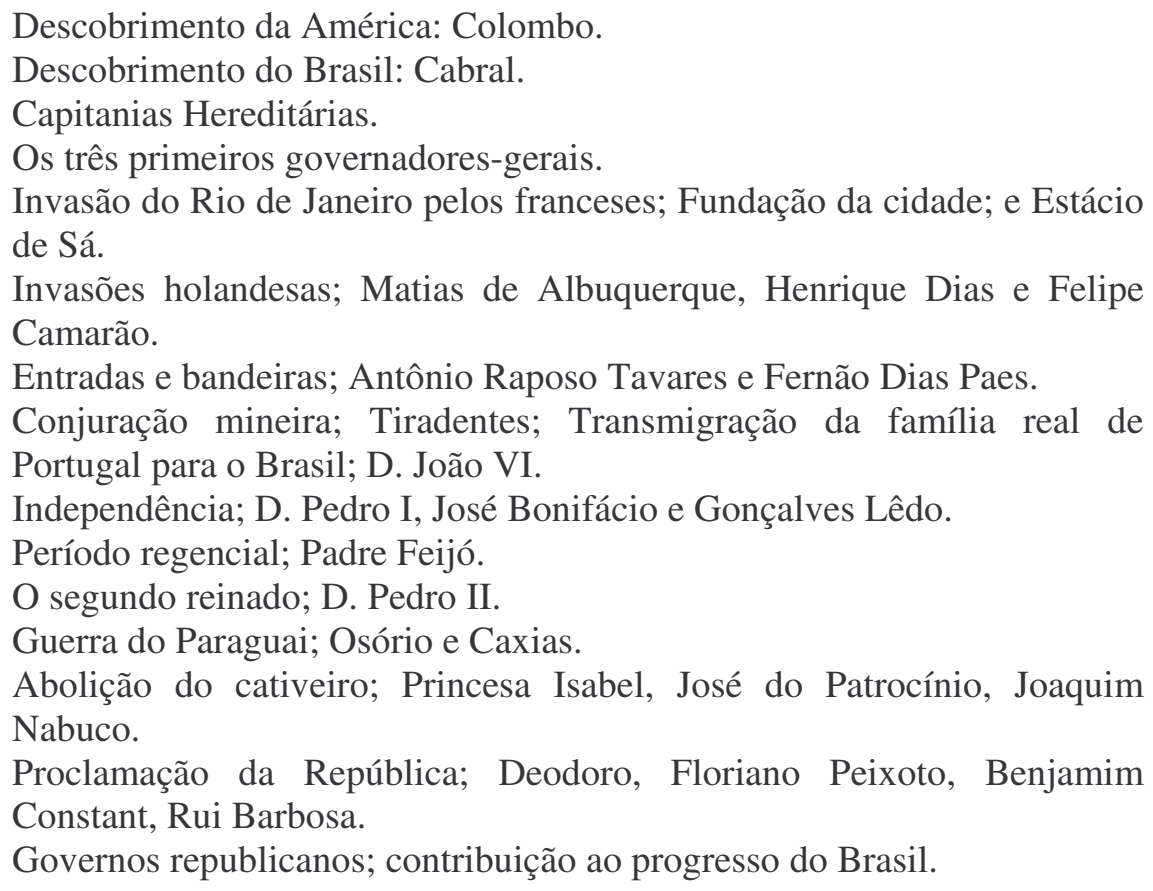

No capítulo 5, a Portaria 501/1952 instrui acerca dos tempos dos trabalhos escolares que, no ginasial, não deveria exceder 24 horas semanais. Na distribuição dessas horas couberam tanto à História do Brasil quanto à História Geral 2 horas semanais, sendo a História do Brasil, anteriormente ministrada na $3^{\mathrm{a}}$ e $4^{\mathrm{a}}$ séries, ministrada, a partir daí, para a $1^{\mathrm{a}}$ série e permanecendo na $4^{\mathrm{a}}$; a História Geral, anteriormente ministrada para a $1^{\mathrm{a}}$ e a $2^{\mathrm{a}}$ séries, permaneceu na $2^{\mathrm{a}}$, passando a ser ministrada na $3^{\mathrm{a}}$ e na $4^{\mathrm{a}}$ séries.

Segundo Romanelli (1989, p. 159), a Lei Orgânica do Ensino Secundário mantinha o sistema de provas e exames permanecendo praticamente o mesmo, mantendo-se, assim, a tradição de rigidez e seletividade. Também a Portaria 501/1952 em nada alterou o sistema de avaliação. Permaneceram a realização de duas provas parciais anuais, escritas, a realização da prova final, oral, perante banca examinadora e os exames de $2^{\mathrm{a}}$ época concedidos aos alunos que não conseguiam alcançar a média ou para aqueles que, por motivo de doença, houvessem faltado às provas. Em conformidade com seu Regulamento Interno o Ginásio Frei Rogério seguia essas prescrições, conforme pode ser observado nos muitos relatórios de pontos organizados para as provas parciais, provas finais e exames de $2^{a}$ época. Exemplificamos no quadro 1: 
Quadro 1: Transcrição dos Pontos da 1ª e da 2 ${ }^{\text {a }}$ Prova Parcial de História do Brasil/1945

\begin{tabular}{|c|c|}
\hline $\begin{array}{l}\text { Pontos organizados para a } 1^{\text {a }} \text { Prova Parcial } \\
\text { História do Brasil realizada em 14/06/1945 } \\
3^{\text {a }} \text { série }\end{array}$ & $\begin{array}{c}\text { Pontos organizados para a } 2^{\text {a }} \text { Prova Parcial } \\
\text { História do Brasil realizada em out./1945 } \\
3^{\text {a }} \text { série }\end{array}$ \\
\hline $\begin{array}{l}1^{\circ} \text { ponto a) Bandeiras } \\
\text { b) Dinastia de Borgonha } \\
\text { c) Família e usos dos índios } \\
2^{\circ} \text { ponto a) Capitanias } \\
\text { b) Raça Ariana } \\
\text { c) Religião e governo dos índios } \\
3^{\circ} \text { ponto a) República dos Palmares } \\
\text { b) Os nomes do Brasil } \\
\text { c) Paraíba, Sergipe e RN } \\
4^{\circ} \text { ponto a) Classificação do indígena } \\
\text { b) Tomé de Sousa } \\
\text { c) A carta de Vaz de Caminha }\end{array}$ & 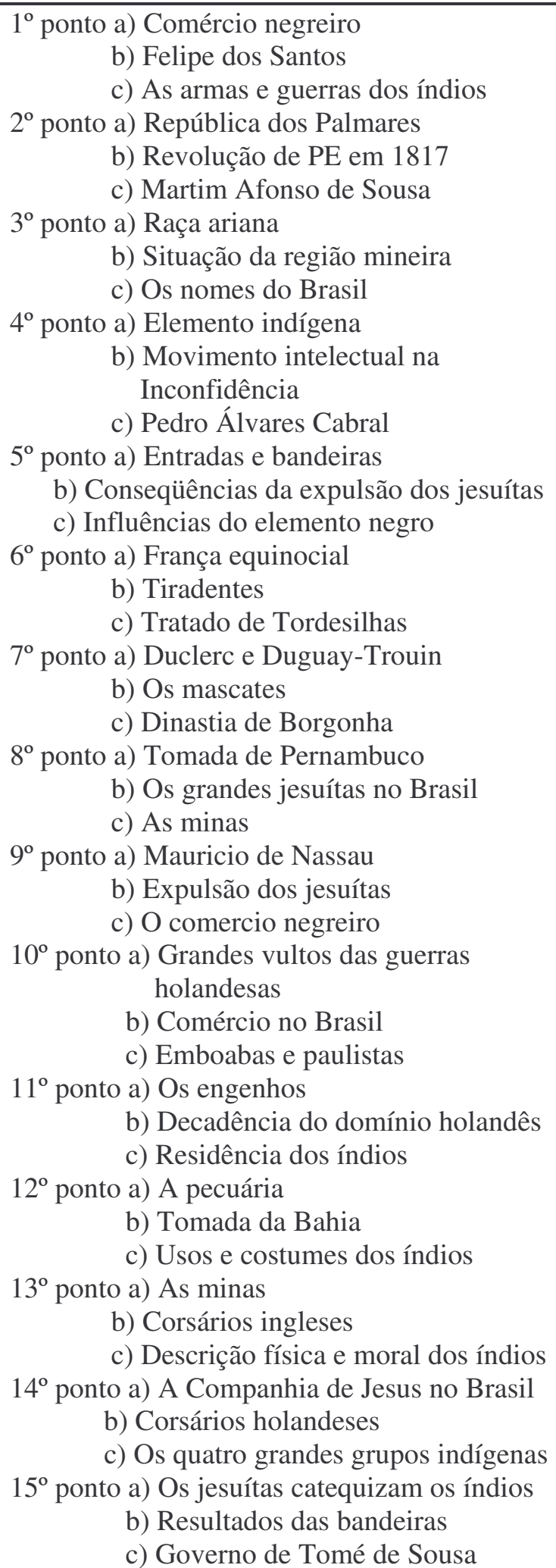 \\
\hline
\end{tabular}




\begin{tabular}{|c|c|}
\hline \multicolumn{2}{|l|}{ Continuação do Quadro 1} \\
\hline & $\begin{array}{l}16^{\circ} \text { ponto a) Reduções } \\
\text { b) Colônia do Sacramento } \\
\text { c) Governo de Mem de Sá } \\
17^{\circ} \text { ponto a) Lutas entre colonos e jesuítas } \\
\text { b) Principais bandeirantes } \\
\text { c) Resultados das Capitanias } \\
18^{\circ} \text { ponto a) O ensino no Brasil } \\
\text { b) Os roteiros } \\
\text { c) Criação das Capitanias } \\
19^{\circ} \text { ponto a) Emboabas e paulistas } \\
\text { b) Conquistas das religiões sedentrionais } \\
\text { c) O tipo brasileiro } \\
20^{\circ} \text { ponto a) As Câmaras, berço da liberdade } \\
\text { b) Culturas várias } \\
\text { c) O elemento africano }\end{array}$ \\
\hline
\end{tabular}

Fonte: Relatório Anual de 1945/Arquivo do Colégio Marista Frei Rogério/Joaçaba, SC.

Optamos, ao elaborar o relatório de pesquisa, somente pela transcrição acima exposta devido ao grande número de relatórios constando os pontos para provas parciais, provas finais e exames de $2^{a}$ época. Não se deixou, porém, de analisar os conteúdos de tais documentos. Isto posto, segue a análise.

As alterações promovidas pelo Ministério da Educação, em 1951, fizeram uma redistribuição dos conteúdos por série nos cursos ginasial e colegial. Em 1945 o ensino da História do Brasil estava presente na $3^{\mathrm{a}}$ série, como pode ser observado no quadro 1 . A partir de 1951 a História do Brasil vai para a $1^{\mathrm{a}}$ e a $4^{\mathrm{a}}$ séries.

A comparação dos conteúdos expostos nos relatórios de pontos para as provas revela o cumprimento das instruções prescritas pelo Ministério da Educação na disciplina História no Ginásio Frei Rogério. Os conteúdos prescritos que não aparecem na relação acima transcrita constam na relação de matéria para as provas das outras séries, quais sejam: Descobrimento da América: Colombo; Invasão do Rio de Janeiro; Fundação da cidade; Estácio de Sá. Transmigração da família real de Portugal para o Brasil; D. João VI; Independência; D. Pedro I, José Bonifácio e Gonçalves Lêdo; Período regencial; Padre Feijó. O segundo reinado; D. Pedro II. Guerra do Paraguai; Osório e Caxias. Abolição do cativeiro; Princesa Isabel, José do Patrocínio, Joaquim Nabuco; Proclamação da República. Após 1951 houve a redistribuição da seriação desses conteúdos sem, contudo, alterá-los. Contudo, chama a atenção, no currículo de História trabalhado pelos professores do Frei Rogério, a ênfase dada à ação dos jesuítas, especificamente nos pontos Grandes vultos missionários e Os grandes jesuítas no Brasil. pontos constantes nas relações de pontos para as provas, mas que não constam na relação de conteúdos impostos pela Portaria 501/1952. Nas instruções do Ministério da Educação destacam-se os grandes vultos da Pátria relacionados ao descobrimento, ao império, à independência e à república, mas não os missionários, que são apenas citados, mas não referenciados como aparece nos documentos do Ginásio Frei Rogério.

Assim como os pontos para a História do Brasil, os pontos para a História Geral seguiam, também, as recomendações do Ministério da Educação: 
Quadro 2: Transcrição dos Pontos da 1a Prova Parcial de História Geral/1944

\begin{tabular}{|c|c|}
\hline $\begin{array}{c}\text { Pontos organizados para a } 1^{\text {a }} \text { Prova Parcial de } \\
\text { História Geral - } 3^{\text {a }} \text { série/1944 }\end{array}$ & \\
\hline $\begin{array}{l}1^{\circ} \text { Ponto a) Definição e divisão de História } \\
\text { b) Importância do rio Nilo } \\
\text { c) Hieróglifo e escrita cuneiforme } \\
2^{\circ} \text { Ponto a) Definição e divisão dos tempos } \\
\text { pré-históricos } \\
\text { b) Civilização egípcia: religião, } \\
\text { classes sociais, artes } \\
\text { c) Felipe de Macedo } \\
\text { Mesopotâmica } \\
3^{\circ} \text { Ponto a) Resumo história da Civilização } \\
\text { b) Os estados gregos } \\
\text { c) A Índia e o Bramanismo } \\
4^{\circ} \text { Ponto a) Resumo história da Civilização } \\
\text { Hebraica } \\
\text { b) Alexandre Magno } \\
\text { c) Letras, artes e ciências entre os hindus } \\
5^{\circ} \text { Ponto a) A Grécia no séc. de Péricles } \\
\text { b) Resumo história da Civilização Fenícia } \\
\text { c) Fontes da história }\end{array}$ & $\begin{array}{l}6^{\circ} \text { Ponto a) História da Civilização Egípcia } \\
\text { b) Guerras medo-pérsicas } \\
\text { c) Divisão da história da Índia } \\
7^{\circ} \text { Ponto a) A Grécia após a morte de } \\
\text { Alexandre Magno } \\
\text { b) Apreciação geral da Civilização grega } \\
\text { c) Campanha budista na Índia } \\
8^{\circ} \text { Ponto a) Populações primitivas gregas } \\
\text { b) Guerras civis na Grécia } \\
\text { c) Esparta e Atenas, Licurgo e Solon } \\
9^{\circ} \text { Ponto a) Principais divindades da } \\
\text { mitologia grega } \\
\text { b) História da Civilização Persa } \\
\text { c) Necessidade do estudo da História } \\
10^{\circ} \text { Ponto a) Principais atividades da } \\
\text { Civilização Fenícia } \\
\text { b) Escrita assíria e egípcia: } \\
\text { aparecimento do alfabeto } \\
\text { c) Péricles e seu papel na história grega }\end{array}$ \\
\hline
\end{tabular}

Fonte: Relatório Anual de 1944/Arquivo do Colégio Marista Frei Rogério/Joaçaba, SC.

Os relatórios constando os pontos das provas parciais, das provas finais e dos exames de $2^{\mathrm{a}}$ época eram assinados pelo inspetor geral e enviados à Diretoria de Divisão do Ensino Secundário no Rio de Janeiro.

Quanto à carga horária das disciplinas, entre elas a História, no Ginásio Frei Rogério, em 1943-1944, estava assim distribuída:

Quadro 3: Transcrição do Mapa das aulas dadas por bimestre/Relatório 1943-1944

\begin{tabular}{|l|l|l|l|l|l|l|l|l|}
\hline & $\begin{array}{l}1^{\mathbf{o}} \\
\text { bimestre }\end{array}$ & $\begin{array}{l}2^{\mathrm{o}} \\
\text { bimestre }\end{array}$ & $\begin{array}{l}3^{\mathrm{o}} \\
\text { bimestre }\end{array}$ & $\begin{array}{l}4^{\mathrm{o}} \\
\text { bimestre }\end{array}$ & \\
\hline & $1^{\mathrm{a}}$ série & $2^{\mathrm{a}}$ série & $1^{\mathrm{a}}$ série & $2^{\mathrm{a}}$ série & $1^{\mathrm{a}}$ série & $2^{\mathrm{a}}$ série & $1^{\text {a }}$ série & $2^{\mathrm{a}}$ série \\
\hline Português & 27 & 20 & 28 & 21 & 16 & 12 & 16 & 12 \\
\hline Latim & 20 & 25 & 21 & 22 & 12 & 12 & 12 & 12 \\
\hline Francês & 20 & 21 & 22 & 22 & 12 & 12 & 12 & 12 \\
\hline Matemática. & 20 & 21 & 21 & 21 & 12 & 12 & 12 & 12 \\
\hline Hist. Geral & 13 & 13 & 15 & 14 & 08 & 08 & 08 & 08 \\
\hline Geog. Geral & 13 & 13 & 15 & 14 & 08 & 08 & 08 & 08 \\
\hline Trab. Manuais & 20 & 13 & 21 & 14 & 08 & 08 & 08 & 08 \\
\hline Desenho & 15 & 14 & 14 & 14 & 08 & 08 & 08 & 08 \\
\hline $\begin{array}{l}\text { Ciênc. } \\
\text { Naturais }\end{array}$ & 13 & 13 & 14 & 14 & 08 & 08 & 08 & 08 \\
\hline Inglês & - & 20 & - & 22 & - & 12 & - & 12 \\
\hline
\end{tabular}

Fonte: Relatório Anual de 1943-1944/Arquivo do Colégio Marista Frei Rogério/Joaçaba, SC.

Em 1945, foi implantada a $3^{\text {a }}$ série ginasial e nela ministrada a História do Brasil conforme quadro 4 - permanecendo a $1^{\mathrm{a}}$ e a $2^{\mathrm{a}}$ séries com a História Geral. Esse quadro se modificou em 1952, quando a Portaria $501 \mathrm{fez}$ a redistribuição das disciplinas, ficando a História do Brasil na $1^{\mathrm{a}}$ e na $4^{\mathrm{a}}$ séries e a História Geral para a $2^{\mathrm{a}}$ e $3^{\mathrm{a}}$ séries. 
Quadro 4: Transcrição do Mapa das aulas dadas por bimestre/Relatório 1945

\begin{tabular}{|l|l|l|l|l|l|l|l|l|l|l|l|l|l|l|l|}
\hline & $\begin{array}{l}1^{\mathrm{o}} \\
\text { bimestre }\end{array}$ & & $\begin{array}{l}2^{\mathrm{o}} \\
\text { bimestre }\end{array}$ & & $\begin{array}{l}3^{\mathrm{o}} \\
\text { bimestre }\end{array}$ & & & $\begin{array}{l}4^{\mathrm{o}} \\
\text { bimestre }\end{array}$ & & & & & \\
\hline & $1^{\mathrm{a}}$ & $2^{\mathrm{a}}$ & $3^{\mathrm{a}}$ & $1^{\mathrm{a}}$ & $2^{\mathrm{a}}$ & $3^{\mathrm{a}}$ & $1^{\mathrm{a}}$ & $2^{\mathrm{a}}$ & $3^{\mathrm{a}}$ & $1^{\mathrm{a}}$ & $2^{\mathrm{a}}$ & $3^{\mathrm{a}}$ & $1^{\mathrm{a}}$ & $2^{\mathrm{a}}$ & $3^{\mathrm{a}}$ \\
\hline Português. & 24 & 18 & 18 & 27 & 19 & 19 & 36 & 27 & 27 & 16 & 12 & 12 & 14 & 12 & 12 \\
\hline Latim & 18 & 18 & 24 & 19 & 19 & 26 & 27 & 27 & 36 & 12 & 12 & 16 & 12 & 12 & 14 \\
\hline Francês & 18 & 18 & 18 & 19 & 19 & 19 & 27 & 27 & 27 & 12 & 12 & 12 & 12 & 12 & 12 \\
\hline Matemática & 18 & 18 & 18 & 19 & 19 & 19 & 27 & 27 & 27 & 12 & 12 & 12 & 12 & 12 & 12 \\
\hline Hist. Geral & 12 & 12 & - & 14 & 14 & - & 18 & 18 & - & 08 & 08 & - & 09 & 08 & - \\
\hline Geo. Geral. & 12 & 12 & - & 14 & 14 & - & 18 & 18 & - & 08 & 08 & - & 08 & 08 & - \\
\hline $\begin{array}{l}\text { Trabalhos } \\
\text { Manuais }\end{array}$ & 18 & 12 & - & 20 & 13 & - & 27 & 18 & - & 12 & 08 & - & 12 & 08 & - \\
\hline Desenho. & 12 & 12 & 06 & 13 & 13 & 06 & 18 & 18 & 09 & 08 & 08 & 08 & 08 & 08 & 08 \\
\hline $\begin{array}{l}\text { Canto } \\
\text { Orfeônico }\end{array}$ & 12 & 12 & 06 & 13 & 12 & 06 & 18 & 18 & 09 & 08 & 08 & 09 & 08 & 08 & 08 \\
\hline Inglês & - & 18 & 18 & - & 19 & 19 & - & 27 & 27 & - & 12 & 12 & - & 12 & 12 \\
\hline $\begin{array}{l}\text { Ciências } \\
\text { Naturais }\end{array}$ & - & - & 18 & - & - & 18 & - & - & 27 & - & - & 12 & - & - & 12 \\
\hline $\begin{array}{l}\text { História do } \\
\text { Brasil }\end{array}$ & - & - & 12 & - & - & 12 & - & - & 18 & - & - & 08 & - & - & 08 \\
\hline $\begin{array}{l}\text { Geografia } \\
\text { do Brasil }\end{array}$ & - & - & 12 & - & - & 12 & - & - & 18 & - & - & 08 & - & - & 08 \\
\hline
\end{tabular}

Fonte: Relatório Anual de 1945/Arquivo do Colégio Marista Frei Rogério/Joaçaba, SC.

Quanto aos materiais didáticos utilizados, consta no Relatório para Fins de Reconhecimento/1953, que "o material didático está quase completamente de acordo com as prescrições da Portaria 501 de 19 de maio de 1952". Quanto a esse aspecto a Portaria traz, no capítulo VII, instruções relativas à adoção dos livros didáticos que deverão ser aqueles aprovados pela Comissão Nacional do Livro Didático, vedando "à direção do educandário estabelecer preferências entre os livros didáticos autorizados, sendo livre aos professores a escolha dos mesmos, para seus alunos, uma vez que constem da relação oficial das obras de uso autorizado." (Artigo 43, § $4^{\circ}$ ). O Ginásio Frei Rogério, em seu Regulamento Interno de 1944, portanto anterior à Portaria, já delegava a seus professores a obrigação de indicar os livros didáticos destinados ao estudo da matéria. No caso da História encontramos somente duas informações sobre os livros adotados: História Geral para $1^{a}$ série ginasial, editado pela FTD, utilizado em 1943 e História Geral: Coleção FTD, em 1944.

\subsection{O ESPAÇO FÍSICO}

O espaço físico é um aspecto mais geral da organização do trabalho didático quando se pesquisa uma disciplina específica, isto porque um mesmo espaço, na maioria das vezes, envolve o ensino de quase todas as disciplinas.

No caso do Ginásio Frei Rogério havia, além de oito salas de aula normais, as salas especiais destinadas ao ensino de Geografia, de Línguas Vivas, de Desenho, de Ciências 
Naturais, de Antropologia, de Zoologia, de Mineralogia, de Botânica e de Química dispondo de materiais didáticos próprios ao ensino dessas matérias5.

O prédio contava ainda com um auditório no andar superior destinado a encontros com os alunos, reuniões com os pais, apresentações, eventos culturais e palestras; uma sala para os professores, uma secretaria e a capela com celebração diária da missa. Anexo ao Ginásio havia o ginásio de esportes e o internato.

A biblioteca contava com 182 obras, todas da FTD, editora que pertence à Congregação Marista. Dentre elas oito volumes sobre a História da Civilização, sendo cinco didáticos.

As carteiras eram duplas e a mesa do professor localizava-se sobre um estrado, em um nível mais alto, permitindo ampla visão e controle da sala, revelando a autoridade máxima do mestre.

\section{CONCLUSÃO}

Fizemos a pergunta à história: como se deu o desenvolvimento histórico temporal da disciplina História? A que necessidade social ela atende? Qual a sua função? Qual a relação entre os conteúdos prescritos e os conteúdos realmente ensinados no Frei Rogério? Como a prática escolar do Ginásio Frei Rogério organizou esta disciplina? Com que finalidades? Buscando entender a organização do trabalho didático relativo à disciplina História encontrou-se os elementos necessários às respostas.

A disciplina História nasceu, segundo Fonseca (2003), a partir da necessidade de formar as elites, quando a organização dos sistemas de ensino público passou a preocuparse com a formação de um cidadão adequado às transformações do sistema social e econômico provocadas pela consolidação do capitalismo e pelo fortalecimento das identidades nacionais. Desenvolveu-se com um objetivo definido: conformar o cidadão à sociedade na qual ele vive. Ela entrou nas escolas brasileiras como formadora da identidade nacional e seus objetivos foram traçados girando sempre em volta da formação do cidadão que atendesse às necessidades de seu tempo. Conforme Cardoso (2006, p. 107)

Assim foi na Reforma Francisco Campos/1930, quando o ensino objetivava a retomada da concepção de Estado e o fortalecimento do sentimento de identidade nacional; na Reforma Gustavo Capanema, deveria desenvolver o patriotismo, além de formar a nacionalidade e a identidade nacional; a formação do cidadão ideal para o Estado centralizado e a formação para o mercado de trabalho foram os objetivos propostos na década de 1960, pela Lei 4.024/61; no regime militar, a disciplina Estudos Sociais teve seus conteúdos reduzidos, esvaziados e cuidados para que não despertassem o ódio nem excitassem os ânimos da juventude, buscando formar crianças e adolescentes obedientes à nova ordem.

A disciplina História acompanhou as mudanças ocorridas na sociedade, permanecendo nos currículos, conforme Bittencourt (2003, p. 20), com a clara intenção de formar o cidadão político, não o cidadão social: "O papel da História como disciplina encarregada da formação do cidadão político não é velado ou implícito, como ocorre com as demais disciplinas".

Na prática escolar do Ginásio Frei Rogério não foi muito diferente. Na análise das relações dos pontos para as provas, da carga horária, dos livros adotados e dos demais documentos constatou-se que o Ginásio seguia as instruções impostas pelo Ministério da Educação. Tal constatação é confirmada pelo Relatório para Fins de Reconhecimento no 
qual o inspetor federal Leônidas Menel afirma: "o ensino ministrado pelo Ginásio Frei Rogério é eficiente [...] e seguem as instruções metodológicas da Diretoria do Ensino Secundário para as diversas disciplinas".

A História, assim como as demais disciplinas, foi, e continua sendo, elaborada com o intuito de formar cidadãos conformados à ordem dominante. Também no Ginásio Frei Rogério a História foi organizada de forma a cumprir esta função; sua identidade foi mantida. O elemento singular, característico dessa instituição, é dado pela vertente religiosa: formar o cidadão não apenas "virtuoso", mas também "bom cristão". Nesse sentido é que se explica a ênfase dada, na disciplina História, às ações dos jesuítas no estudo da História do Brasil, conteúdo que extrapola as prescrições governamentais. Além disso, o Ginásio, no período estudado, contava com aulas de ensino religioso e com uma capela em seu interior onde eram celebradas missas diárias, conforme nos relatou um dos ‘irmãos' que há muito tempo reside nas dependências do próprio Ginásio. Ao extrapolarem os conteúdos prescritos, enfatizando a ação religiosa presente na História do Brasil, incutiam nas mentes dos educandos a importância da ação divina na história da humanidade revelando o propósito religioso intrínseco à ação pedagógica. A História ensinada no Frei Rogério contribuíra, sim, para formar o cidadão virtuoso, mas acima de tudo formara o bom cristão, o católico "praticante".

Considerando que cada escola materializa as diretrizes prescritas de maneira diferenciada, adequando-a aos seus princípios, temos o Ginásio Frei Rogério como o exemplo claro dessa adequação. Ao enfatizar conteúdos que, embora prescritos, são considerados menos relevantes pela legislação governamental, como foi o caso da ação jesuítica, o Ginásio referendou o que era relevante na sua concepção: fomentou a interpretação cristã da vida, transmitindo o sentido de Deus. Contudo, entre o cidadão virtuoso e bom cristão, objetivado pela pedagogia marista e o cidadão político da proposta governamental não há incompatibilidades, uma vez que Igreja e Estado caminhavam juntos defendendo os mesmos interesses: formar o cidadão submisso, aquele que exerce bem seus deveres e, embora conheça seus direitos não é capaz de exercê-los sem depender de outrem.

\section{REFERÊNCIAS}

ABUD, K. (2004). Currículos de História e Políticas Públicas: os programas de História do Brasil na Escola Secundária. In: BITTENCOURT, C. (org.) O saber histórico na sala de aula. $2^{a}$ ed. São Paulo: Contexto.

ALVES, G. L. (2005) O Trabalho Didático na Escola Moderna. Campinas: Autores Associados.

BITTENCOURT, C. (2003). Disciplinas Escolares: história e pesquisa. In: OLIVEIRA; RANZI (org.). História das Disciplinas Escolares no Brasil: contribuições para o debate. Bragança Paulista: EDUSF.

(2005). Ensino de História: Fundamentos e Métodos. São Paulo: Cortez Editora.

BRASIL. Lei Orgânica do Ensino Secundário - Portaria Ministerial no 170, de 11 de Julho de 1942.

Portaria no 501 de 19 de maio de 1952. São Paulo: Editora do Brasil/Ministério da Educação e Saúde/Diretoria do Ensino Secundário. 
Lei n. 4.024 de 20 de dezembro de 1961: Fixa as Diretrizes e Bases da Educação Nacional. In: Diretrizes e Bases da Educação Nacional. (1968). Coleção A. E. C. 12. 3 ed. Rio de Janeiro: MEC/COLTED.

Parecer 853/71 do Conselho Federal de Educação (aprovado em 12.11.1971). Núcleo comum para os currículos do ensino de $1^{\circ}$ e $2^{\circ}$ graus. A doutrina do currículo na Lei n. 5.692. In VASCONCELLOS, J. (1972). Legislação Fundamental: ensino de $\mathbf{1}^{\mathbf{0}} \mathbf{e}$ $\mathbf{2}^{\mathbf{0}}$ graus. São Paulo: LISA - Livros Irradiantes.

Resolução n. 8, de $1^{\circ}$ de dezembro de 1971, anexa ao Parecer n. 853/71. Fixa o núcleo comum para os currículos do ensino de $1^{\circ}$ e $2^{\circ}$ graus, definindo-lhes os objetivos e a amplitude. In VASCONCELLOS, J. (1972). Legislação Fundamental: ensino de $\mathbf{1}^{\mathbf{0}}$ e $\mathbf{2}^{\mathbf{o}}$ graus. São Paulo: LISA - Livros Irradiantes.

Lei n. 5.692 de 11 de agosto de 1971: Fixa Diretrizes e Bases para o ensino de $1^{\circ} \mathrm{e}$ $2^{\circ}$ graus, e dá outras providências. In: SAVIANI, D. (1987). Política e Educação no Brasil. São Paulo, Cortez: Autores Associados.

Lei de Diretrizes e Bases da Educação no 9.394, de 1996. Brasília.

CARdoso, M. A. (2006). O Ensino de História nas Séries Iniciais do Ensino de Primeiro Grau na Escola Estadual Maria Constança Barros Machado (1977-2002). Dissertação (Mestrado em Educação). Campo Grande: UFMS.

CHERVEL, A. (1990). A História das Disciplinas escolares: reflexões sobre um campo de pesquisa. Revista Teoria e Educação, Porto Alegre, v.2, p. 177-229.

COLÉGIO MARISTA FREI ROGÉRIO. Relatório de Inspeção de 2 de março de 1943. Arquivo do Colégio Marista Frei Rogério/Joaçaba, SC

Relatório Anual de 1943-1944. Arquivo do Colégio Marista Frei Rogério/Joaçaba, SC

Regulamento Interno do Ginásio Frei Rogério, 1944. Arquivo do Colégio Marista Frei Rogério/Joaçaba, SC

Relatório Anual de 1944. Arquivo do Colégio Marista Frei Rogério/Joaçaba, SC

Relatório Anual de 1945. Arquivo do Colégio Marista Frei Rogério/Joaçaba, SC

Relatório para fins de Reconhecimento. 1953. Arquivo do Colégio Marista Frei Rogério/Joaçaba, SC.

DALlABRIDA, N; CARMINATI, C. J. (2007). O Tempo dos Ginásios: ensino secundário em Santa Catarina (final do século XIX, meados do século XX). Campinas: Mercado das Letras; Florianópolis: Universidade do Estado de Santa Catarina.

DETONI, M. Z. (2003) O Ginásio Frei Rogério - Sua Ação Educacional e Política. Dissertação (Mestrado em Educação). Caçador: Universidade do Contestado.

FONSECA, THAIS. N. L. (2003). História e Ensino de História. Belo Horizonte: Autentica.

HOFF, S. (2005). O Manual Didático e o Processo Educativo: lições da História. In SOUZA, A. A. A; FRIAS, R. B. O Processo Educativo na Atualidade: fundamentos teóricos. Campo Grande, MS: Ed. UNIDERP.

MARTINS, Adelino. C. (2003) Estilo Marista de Educar. Porto Alegre: PUC/RS. Disponível em http://www.pucrs.br/conheca/estilomarista/index.htm.

Revista HISTEDBR On-line, Campinas, número especial, p. 194-214, mai.2010 - ISSN: 1676-2584 213 
NADAI, Elza. O Ensino de História no Brasil: trajetória e perspectiva. Revista Brasileira de História, São Paulo, v. 13 n. 25/26, p. 143-162, set.1992/ago1993.

ROMANElli, O. O. (1989). História da Educação no Brasil (1930-1973). $11^{\text {a }}$ ed. Petrópolis: Vozes.

Notas:

${ }^{1}$ Texto ampliado a partir da Comunicação apresentada no VIII Seminário Nacional de Estudos e Pesquisas "História, Sociedade e Educação no Brasil", ocorrido entre os dias 30 de junho e 03 de julho de 2009, na Universidade Estadual de Campinas, SP.

${ }^{2}$ Pesquisas realizadas pelo Grupo: Ginásio Frei Rogério em Joaçaba (DETONI, 2003), Ginásio Santa Cruz em Canoinhas (DEUS, 2004), Colégio Cenecista em Concórdia (MEIRELLES, 2005), Colégio São Luiz em São Miguel (SALVI, 2004), Colégio Agrícola Federal de Concórdia (PINHEIRO MACHADO, 2005) e Escola Normal Sagrado Coração de Jesus de Canoinhas (LONGHI; HOFF, 2008).

3 Dados colhidos, em 09/12/2008, no site: www.maristas.org.br (nossos colégios/Frei Rogério/A Escola/história/link Histórico do Colégio Frei Rogério); na dissertação de Marilena Detoni; e em documentos constantes no arquivo do próprio Colégio.

${ }^{4}$ O link Histórico do Colégio Frei Rogério, que em 2008 podia ser acessado no site citado na nota 3, em 2010 não está mais disponível. Contudo, se houver interesse o temos, em pdf, em nossos arquivos.

${ }^{5}$ A descrição completa da construção do edifício, suas dependências, salas de aula, equipamentos, materiais didáticos, estrutura física como condições de luminosidade, contenção de ruídos, dentre outros, encontra-se no Relatório de Inspeção datado de 2 de março de 1943, assinado pelo inspetor federal Elpídio Caetano da Silva quando de sua visita para inspecionar a obra para que pudesse, então, ser entregue à comunidade.

Artigo recebido em: 04/04/2010

Aprovado para publicação em: 12/06/2010 